\title{
The neurological manifestations of trauma: lessons from World War I
}

\author{
Stefanie C. Linden · Volker Hess $\cdot$ Edgar Jones
}

Received: 28 March 2011/Accepted: 5 October 2011/Published online: 8 November 2011

(C) The Author(s) 2011. This article is published with open access at Springerlink.com

\begin{abstract}
Changes in the clinical presentation of functional disorders and the influence of social and cultural factors can be investigated through the historical case notes from mental hospitals. World War I (WWI) was a potent trigger of functional disorders with neurological or psychiatric symptoms. We analysed 100 randomly selected case files of German servicemen admitted to the Department of Psychiatry of the Charité Medical School of Berlin University during WWI and classified them according to contemporaneous and retrospective modern diagnoses. We compared the clinical presentations with accounts in the German and British medical literature of the time. Most patients obtained the contemporaneous diagnosis of 'psychopathic constitution' or hysteria reflecting the general view of German psychiatrists that not the war but an individual predisposition was the basis for the development of symptoms. The clinical picture was dominated by pseudoneurological motor or sensory symptoms as well as pseudoseizures. Some soldiers relived combat experiences in dream-like dissociative states that partly resemble modern-day post-traumatic stress disorder. Most servicemen were classified as unfit for military service but very few of them were granted compensation. Severe functional
\end{abstract}

S. C. Linden $\cdot$ E. Jones

King's Centre for Military Health Research,

Institute of Psychiatry, King's College London, London, UK

S. C. Linden $(\bowtie)$

Centre for the Humanities and Health, King's College London,

Strand, 5th Floor, East Wing, London WC2R 2LS, UK

e-mail: stefanie.linden@kcl.ac.uk

V. Hess

Institute for the History of Medicine, Charité University

Medicine, Berlin, Germany disorders of a neurological character could develop even without traumatic exposure in combat, which is of interest for the current debate on triggers of stress disorders. The high incidence of pseudoseizures accords with the psychiatric literature of the time and contrasts with accounts of war-related disorders in Britain. The tendency of German psychiatrists not to send traumatised servicemen back to active duty also distinguished between German and British practice. Our data contribute to the debate on the changing patterns of human responses to traumatic experience and their historical and social context.

Keywords Hysteria - War - Trauma - Functional disorders $\cdot$ Case records $\cdot$ Historical

\section{Introduction}

The psychological consequences of combat in World War I (WWI) were often dramatic and presented serious manpower problems for the military authorities [30, 35]. The phenomenology and natural history of these stress-induced mental disorders are of interest to today's mental health practitioners because of the increasing awareness of psychological trauma in combat personnel, which poses considerable clinical and social challenges. The psychological traumata of WWI are also of particular theoretical interest because they sparked the first international debate on the origins and mechanisms of functional disorders. This paper will analyse case records from a cohort of traumatised German soldiers from 1915 to 1918 with regard to clinical presentation, triggering events, course and treatment response. We will also discuss the causal explanations given by clinicians and put them in the context of the contemporaneous biopsychological debates. 
A key question in the medical debates of WWI was whether the behavioural and neurological symptoms found in soldiers without visible wounds were the result of organic brain damage, produced by shock waves from explosions or were psychological effects of traumatic experience; a debate which is currently being re-run on the issue of mild traumatic brain injury (mTBI). British medicine remained ambivalent about this issue and organic interpretations prevailed long into the war, epitomised by the label 'shell shock'. In Germany, the supporters of an organic interpretation, who were led by the Berlin-based neurologist Hermann Oppenheim (1858-1919), were soon outnumbered by the much larger group of neurologists and psychiatrists who attributed functional neurological symptoms to psychological causes, using the label of 'Hysterie' (hysteria). Oppenheim's main opponent, the Hamburg physician Max Nonne (1861-1959) promoted the treatment of war neurosis with suggestion under hypnosis [38]. Another crucial question was whether war was the causative factor in the genesis of the hysterical symptoms, or whether an underlying 'psychopathic' predisposition was the primary agency. This question was not only relevant from the perspective of psychological theory and naturenurture debates, but also determined the practical issues of compensation and pensions.

Most modern accounts of shell shock and related phenomena are based on medical publications from WWI [30, 47] rather than clinical records of the time. Most research into British cases was based on pension files [25] and the admission records of army psychiatric units established close to the frontline [23]. On the German side, Lemke [29] reported contemporaneous diagnoses of 2,000 soldiers admitted to the Department of Psychiatry of Jena University, then headed by Otto Binswanger (1852-1929). However, no study has assessed the psychopathology and neurological symptoms of German combatants in detail and classified them according to present-day diagnostic categories. Interestingly, one of the most systematic studies of war syndromes was published in 1920 by the German psychiatrist and later Communist activist Fritz Fraenkel (1892-1944). Based on his thesis supervised by Karl Bonhoeffer (1868-1948) (Fig. 1), Fraenkel described a sample of 72 patients, mainly soldiers, who had been admitted in 1916 to the Department of Psychiatry of the Charité, the teaching hospital of Berlin University, which was then headed by Bonhoeffer [6]. Fraenkel provided a statistical analysis of the frequencies of different functional neurological syndromes and concluded that a psychopathic constitution was the causative factor in the development of a neurosis. The present paper is based on a similar sample of admissions of military personnel to the Charité from 1915 to 1918.

This study explores the distribution of functional syndromes across the whole period of the war. It also

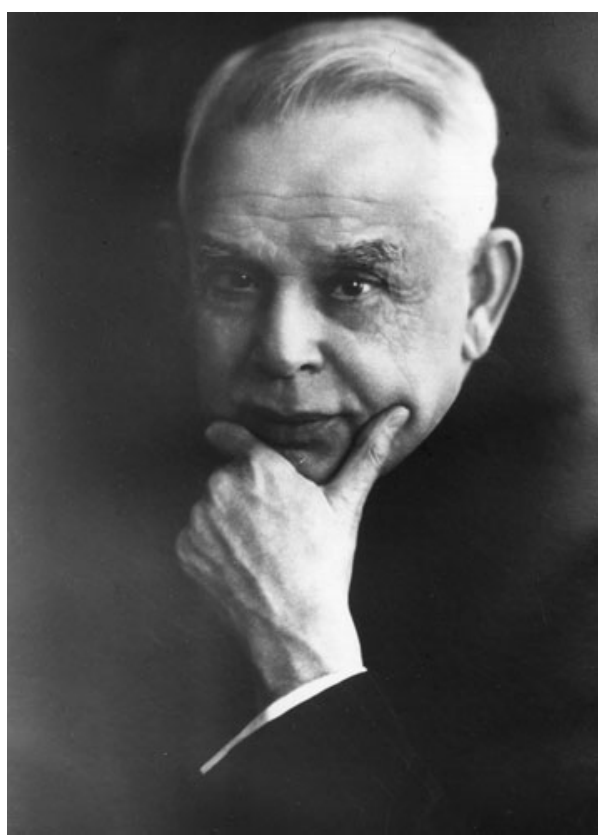

Fig. 1 Karl Bonhoeffer (1968-1948), around the time of his retirement from the chair in psychiatry at the Charite in 1937. Source Bildarchiv des Instituts für Geschichte der Medizin, Charité Berlin

documents the views of the hospital's clinicians on the relative roles of war trauma and predisposing factors ('psychopathic constitution'), while a third aim is to analyse the frequency of the different treatments and assess their reported effects. Finally, we classified the cases according to modern diagnostic criteria to provide a basis for comparisons with other countries and across time.

\section{Methods}

During WWI, 1043 servicemen were admitted to the Department of Psychiatry of the Charité (1914: 217, 1915: 357, 1916: 212, 1917: 152, 1918: 105). We randomly selected 100 servicemen $(9.6 \%$ of the whole sample; 25 cases each from 1915, 1916, 1917 and 1918). A random number sequence was generated for all admission numbers by year and 25 subjects selected for each of the 4 years. The case records provide a precise account of the soldier's war experience, his biography, presenting symptoms and response to treatment. During WWI, the 'Psychiatrische und Nervenklinik' (department for psychiatric and nervous disorders) of the Charite had the status of a military hospital. The department comprised a neurological and a psychiatric wing and served as an admission unit for diagnostic assessment and initiation of treatment within the network of psychiatric hospitals in Berlin. The treatment of mentally ill servicemen was subordinated to the military authorities who regularly sent their patients directly to the 
Charité, which also had the status of a training unit for military doctors. The Berlin case files include detailed descriptions of symptoms, their course during admission, a thorough clinical examination (including an in-depth neurological and cognitive assessment), interviews of family members and detailed assessments by other specialists such as ENT surgeons, dermatologists, neurologists and general physicians. The structure of the case files is illustrated in the extracts in the 'Appendix: case vignette' (see Fig. 2).

We extracted contemporaneous diagnoses from the case notes. We also assigned the presenting symptoms to 10 syndrome categories (1: Psychotic; 2: Affective; 3: Adjustment disorders; 4: Personality disorders; 5: Sensorymotor conversions [motor: gait disorders, paralyses, contractures, speech disorders; sensory: disturbances of sensation, hearing, vision]; 6: Functional seizures; 7: Somatoform disorders; 8: Other dissociative syndromes [other than dissociative disorders of movement and sensation covered under 5 and 6]; 9: Organic disorders; 10: No mental disorder). Finally, the author S.L. diagnosed all cases according to ICD-10 criteria. The diagnosis was based on all information found in the case records including the

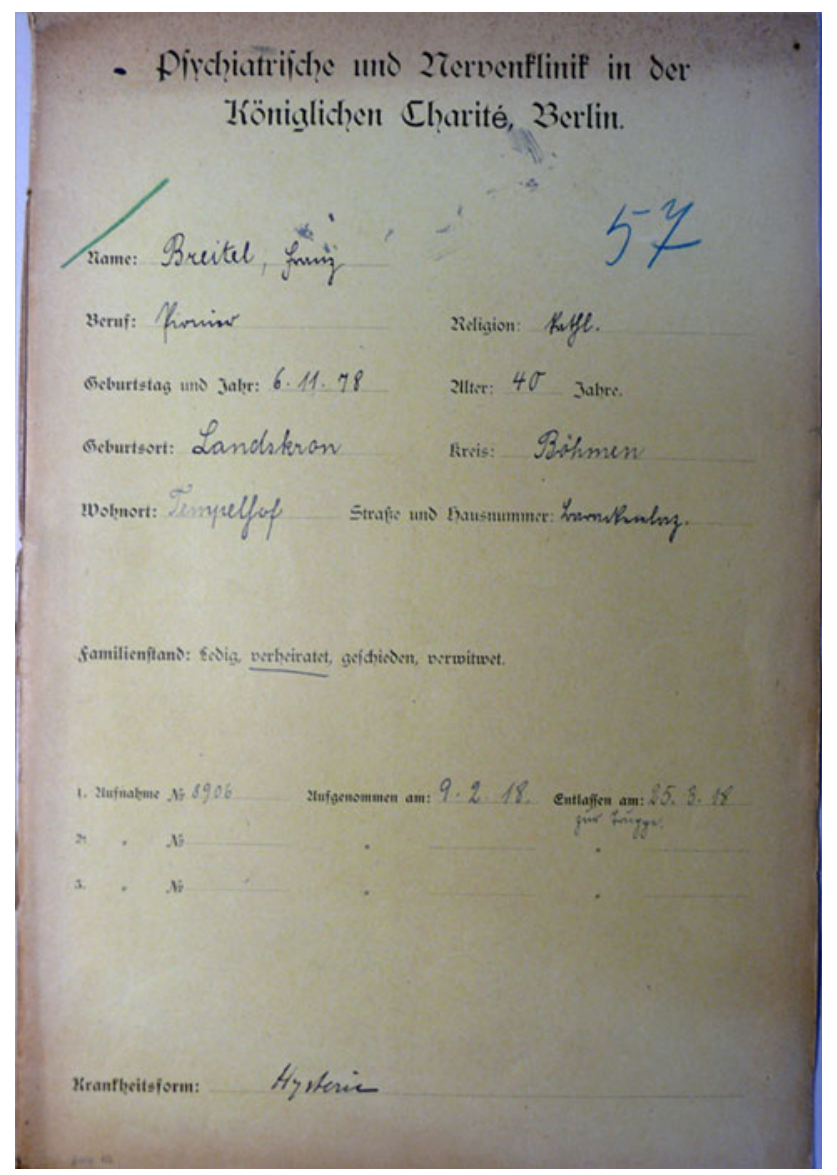

Fig. 2 Cover of a medical record from the Department of Psychiatry at the Charite from 1918. For details, see the case vignette. Source Historisches Psychiatriearchiv Charité Berlin, M8906/1918 onset of symptoms, the presenting mental state and the clinical course of the disorder. All diagnoses were reviewed by an independent consultant psychiatrist (D.L.) with high inter-rater reliability (Cohen's $k=92.5 \%$ [4]).

\section{Results}

\section{Description of sample}

The demographics of the sample are documented in Table 1. Nearly half of the soldiers of our sample were transferred from military hospitals in Berlin or nearby, whereas 25 soldiers were directly sent by their combat units, 14 came from other hospitals (including rehabilitation units) or other specialties within the Charité (particularly the departments of medicine and neurology) and the remaining 12 were admitted under other circumstances (from custody, leave from their force or referral from a private neurologist or psychiatrist).

The ratio of officers to men in the wartime German army was 3.6 per 100 (that is 46,622 officers to 1,281904 other ranks and non-commissioned officers [37]), which suggests that commissioned officers were slightly under-represented in our sample. This is in contrast to other accounts of breakdown rates by rank in WWI [21] and WWII [19]. However, admission biases and a tendency to care for officers with mental illness outside the mainstream mental health system in order to protect them from stigma may have contributed to their under-representation and the overall small number of officers in our sample does not allow drawing firm conclusions.

\section{Trigger events and previous psychiatric history}

In $61 \%$ of cases, a specific trigger for the development of symptoms was mentioned (see Table 2). Physical traumata, for example burial and injuries (30\%), were most frequently associated with mental breakdown, followed by psychological traumata (24\%), such as conflicts with superiors or comrades. The majority of cases had been involved in heavy fighting, but almost a quarter (23\%) had never seen action.

Of the 13 soldiers who had experienced mental health problems before the war, 4 had a family history of mental illness in first-degree relatives. Seven had presented with similar syndromes during the war as compared to their prewar presentation ( 3 with psychogenic seizures before the war, 2 with depression, 1 with somatoform disorder and 1 with adjustment disorder).

Nine per cent of soldiers had a history of heavy drinking, mainly associated with battle exposure. Compared to present-day accounts of alcohol misuse in combatants 
Table 1 Sociodemographic data of the selected 100 admissions to the Charité psychiatry department in $1915-1918(n=100)$

\begin{tabular}{|c|c|}
\hline Age & $\begin{array}{l}\text { Mean: } 27.36 \pm 7.05 \\
\text { Range: } 18-46\end{array}$ \\
\hline Marital status & $\begin{array}{l}\text { Single: } 64 \\
\text { Married: } 35 \\
\text { Divorced: } 1\end{array}$ \\
\hline Religion & $\begin{array}{l}\text { Protestant: } 65 \\
\text { Catholic: } 31 \\
\text { Non-denominational: } 4\end{array}$ \\
\hline Occupation & $\begin{array}{l}\text { Lower middle class } \\
\text { (craftsmen): } 47 \\
\text { Working class (unskilled } \\
\quad \text { workers): } 23 \\
\text { Upper middle class: } 19 \\
\text { Artists: } 4 \\
\text { University students: } 2 \\
\text { Regular soldiers: } 2 \\
\text { Not known: } 2\end{array}$ \\
\hline Length of stay & $\begin{array}{l}39.42 \pm 44.60 \text { days } \\
\text { Range: } 1-285 \text { days }\end{array}$ \\
\hline Rank & $\begin{array}{l}\text { Ordinary soldiers: } 88 \\
\text { Non-commissioned officers: } 10 \\
\text { Commissioned officers: } 2\end{array}$ \\
\hline Front-line service & $\begin{array}{l}\text { Yes: } 77 \\
\text { No: } 23\end{array}$ \\
\hline Injuries & $\begin{array}{l}\text { Injury during combat: } 59 \\
\text { No injury: } 39 \\
\text { Accidental self-injury: } 1 \\
\text { Intentional self-injury: } 1\end{array}$ \\
\hline Transferred from & $\begin{array}{l}\text { War hospitals: } 49 \\
\text { Combat units: } 25 \\
\text { Other hospitals: } 14 \\
\text { Other: } 12\end{array}$ \\
\hline Pre-existing mental health problems & $\begin{array}{l}\text { Yes: } 13 \\
\text { No: } 86 \\
\text { No information: } 1\end{array}$ \\
\hline $\begin{array}{l}\text { Positive family history in first-degree } \\
\text { relative }\end{array}$ & $\begin{array}{l}\text { Yes: } 10 \\
\text { No: } 88 \\
\text { Not known: } 2\end{array}$ \\
\hline Suicidal thoughts & $\begin{array}{l}\text { Yes: } 4 \\
\text { No: } 89 \\
\text { Attempt of suicide: } 4 \\
\text { Questionable: } 4\end{array}$ \\
\hline Previous convictions & $\begin{array}{l}\text { No: } 86 \\
\text { Under military law: } 3 \\
\text { Under criminal law: } 10 \\
\text { Under military and criminal } \\
\text { law: } 1\end{array}$ \\
\hline History of heavy drinking & $\begin{array}{l}\text { Yes: } 9 \\
\text { No: } 88 \\
\text { Questionable: } 3\end{array}$ \\
\hline
\end{tabular}

Table 2 Principal event that triggered onset of symptoms $(n=100)$

\begin{tabular}{|c|c|c|}
\hline $\begin{array}{l}\text { Trauma } \\
\text { category }\end{array}$ & Specific trauma & $\begin{array}{l}\text { Number of } \\
\text { men affected }\end{array}$ \\
\hline \multirow[t]{6}{*}{ Physical } & Injury during front-line service & 14 \\
\hline & Burial & 10 \\
\hline & $\begin{array}{l}\text { Accident during construction work } \\
\text { (bridge, dugout, etc.) }\end{array}$ & 3 \\
\hline & Operation & 2 \\
\hline & Tram accident during home leave & 1 \\
\hline & Total physical & 30 \\
\hline \multirow[t]{7}{*}{ Psychological } & Conflict with superior/comrades & 8 \\
\hline & Shell explosion & 8 \\
\hline & Prospect of returning to front line & 4 \\
\hline & Vaccination & 2 \\
\hline & Witness of comrade's injury & 1 \\
\hline & Aircraft bomb raid & 1 \\
\hline & Total psychological & 24 \\
\hline \multirow{2}{*}{$\begin{array}{c}\text { Somatic } \\
\text { illness }\end{array}$} & Flu, syphilis, tuberculosis & 7 \\
\hline & Total somatic illness & 7 \\
\hline \multirow{4}{*}{$\begin{array}{l}\text { No specific } \\
\text { trigger }\end{array}$} & During front-line service & 24 \\
\hline & During service, not front line & 14 \\
\hline & During home leave & 1 \\
\hline & Total no specific trigger & 39 \\
\hline
\end{tabular}

exposed to threatening situations and atrocities, this seems to be a very low prevalence [53].

Diagnoses

The most common contemporaneous diagnoses were 'psychopathic constitution' (45 cases) and hysteria (46 cases). Three cases were diagnosed with depression, 2 with psychosis, 1 with 'traumatic neurosis', 1 with debility, 1 with intercostal neuritis (classified as organic) and one patient did not receive a diagnosis.

Assigning the presenting symptoms to one of our 10 syndrome categories, we obtained the following picture: The largest group of soldiers (43\%) presented with pseudoneurological motor or sensory symptoms, corresponding to ICD-10: F44.4 (in this group, 14 patients had gait disorders, 10 had speech disorders, 17 had trembling or shaking and 8 paralysis or contractures) and F44.6 (in this group, 3 patients suffered from psychogenic deafness and 2 from sensory loss; in all 5 cases of F44.6, there were also dissociative motor symptoms). Twenty-eight per cent of patients had pseudoseizures (corresponding to ICD-10: F44.5), 20\% classical psychiatric syndromes (depression, psychosis, anxiety, PD, anxiety and depression in adjustment disorders, corresponding to ICD-10: F2, F3, F43, F6), $15 \%$ other dissociative disorders (7\% psychogenic confusion (coded as F44.88), 3\% dissociative fugue (F44.1) and 
another 5\% other unspecific dissociative disorders (F44.9)), and $16 \%$ somatoform disorder (corresponding to ICD-10: F45 and F48). Three per cent had a confirmed organic disorder and 1 case did not meet the criteria for any mental disorder (see Table 3). These numbers add up to over $100 \%$ because 27 patients presented with symptoms that met two diagnostic categories. Of the 15 patients presenting with dissociative symptoms (other than dissociative motor, sensory or convulsive symptoms), 5 showed a specific clinical picture of aggression, increased motor activity, re-living of traumatic war experiences, unresponsiveness to external stimuli and amnesia for the episode after regaining full consciousness.

The 85 patients who presented with functional disorders according to modern diagnostic criteria (with medically unexplained symptoms, comprising the ICD-10 categories F44, F45 and F48) were predominantly diagnosed with 'psychopathic constitution' $(n=39)$ or 'hysteria' $(n=42)$ by the Berlin psychiatrists.

In order to determine the impact of combat stress on the manifestation of symptoms, we divided the sample into two groups, those who had $(n=77)$ and those who had not seen action $(n=23)$. Dissociative disorders (F44.1/8/9 excluding dissociative disorders of movement and sensation F44.4/5/6) only occurred in servicemen who had been exposed to combat (this category constituted to $17 \%$ of all cases exposed to combat). This asymmetrical distribution of dissociative disorders was significant (Chi square test, $P=0.035$ ).

\section{Treatment and outcome of treatment}

At discharge, $38 \%$ of cases were classified as in partial remission, $34 \%$ as completely recovered, $26 \%$ as unchanged and one patient died in hospital. However, outcomes were better for dissociative motor disorders (ICD-10: F44.4), where 14 out of $30(47 \%)$ patients recovered completely, 13 were partly remitted and 3 were discharged unchanged, than for dissociative convulsions ( 7 out of 25 recovered completely (28\%), 7 were partially recovered and 11 remained unchanged).

Eighteen patients mainly with dissociative motor disorders received treatment in form of electric shocks. These were commonly applied to the affected body part using a Faradic brush. Hypnosis and suggestion were also occasionally practised. Response to electric shock was reported as being very good, with most patients recovering after a single treatment, though no follow-up studies were reported to test the longer-term effect of treatment. Seventy-two out of the 100 soldiers were assessed regarding their fitness for military service. The largest group $(n=33)$ was classified as unfit for any military service. Twenty-nine soldiers were assigned to duty at home camps, 4 to garrison service and only 6 to general military service including front-line service (see Table 3 ).

\section{Discussion}

To our knowledge, this is the first study of war-related disorders in German combatants of WWI employing current diagnostic criteria. The case files of the Psychiatric Department of the Charité are unique in that they offer a detailed account of psychopathological phenomena in German servicemen with post-combat disorders. Compared with Fraenkel [6] we had the benefit of the comparison with the international literature and modern diagnostic systems and incorporated cases from four, rather than one, years of the war.

Psychopathic constitution in the discussion of the time

The increase of admissions for functional disorders during the war years, which was not matched by an increase in classical psychiatric disorders-schizophrenia, manicdepressive illness and progressive paralysis-was already documented by Bonhoeffer [2]. Whereas the pre-war admission criteria at the psychiatric unit of the Charité continued to apply during WWI [2], the proportion of male patients diagnosed with psychopathic constitution or hysteria increased dramatically from $12 \%$ in 1913 to $36 \%$ in 1915 .

In our sample, only $20 \%$ of patients presented with primarily psychiatric symptoms, mainly depression and anxiety. Our data are in keeping with other studies (e.g. $[45,52])$ which also found that servicemen with predominantly psychiatric presentation were relatively rare.

In our sample, the vast majority of servicemen with functional disorders (characterised by medically unexplained symptoms, comprising the ICD-10 categories of F44, F45 and F48) obtained a diagnosis of 'psychopathic constitution' (39 out of 85 patients, $46 \%$ ) or 'hysteria' (42 out of 85 patients, $49 \%$ ). This classification reflected the view of the Charité psychiatrists that individual predisposition, rather than the trauma of battle, was responsible for the development of symptoms and resulted in only 7 servicemen being granted compensation. This position was shared by the majority of contemporaneous psychiatrists and neurologists [44]. A notable exception was Oppenheim, who had published a monograph on traumatic neuroses in 1889 [39] and supported the view that hysteria could be triggered in anyone.

Psychogenic versus organic origin

The nature-nurture debate on the relevance of an individual's underlying constitution was orthogonal to another 


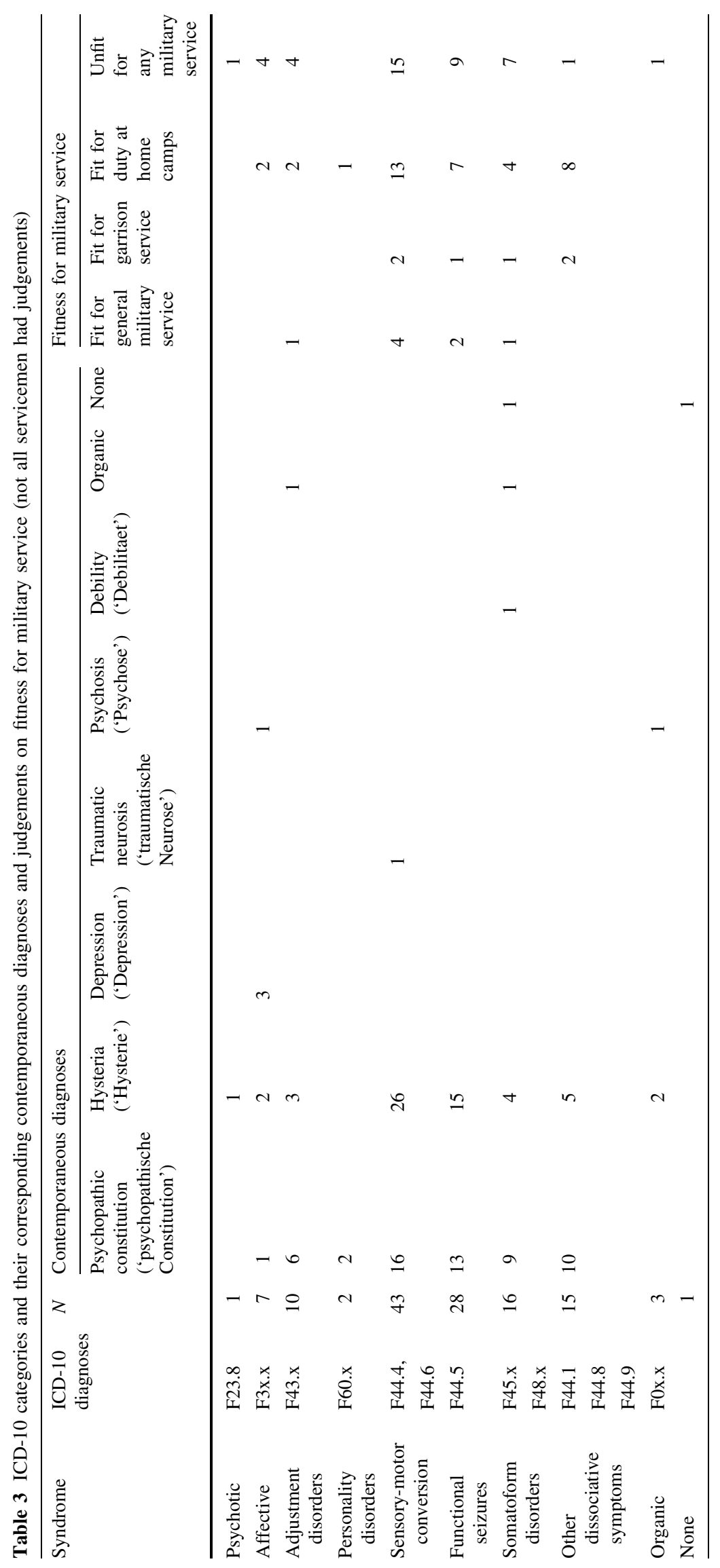


contentious debate of the time, whether functional symptoms were psychogenic in origin or the result of objective pathological changes or lesions. Initially, the most prominent advocates of the organic case were Sarbo [50] and Oppenheim [40]. However, Oppenheim later modified his view and claimed that not only physical trauma but also (psychological) shock could influence physical processes (through the 'vasomotor-secretory-trophic nervous system', which is strikingly similar to modern concepts of neuroendocrine stress responses). Two main arguments were made against organic causation. Firstly, if functional disorders were curable through hypnosis [38] or enforcement [42], then the underlying mechanisms had to be psychological rather than physiological. Secondly, hysterical disorders were not observed in prisoners of war (POW) camps [36], suggesting that symptoms arose only when soldiers were threatened with a return to hazardous combat [36]; yet both modern [22] and contemporaneous [32] research has shown that POWs, too, developed stress disorders.

A middle way was suggested by Moerchen [36], a medical officer at a POW camp in Darmstadt. He argued that psychological trauma or shock could cause subtle organic changes and trigger abnormal biological processes to the nervous system in the same way that psychological therapies (hypnosis, suggestion) could have a positive impact on organic disorders. It took over 80 years for these views to enter mainstream psychiatry [26]. According to Moerchen, the cure or improvement of functional disorders through psychological therapies or the occasional spontaneous remission were compatible with an organic mechanism in the central or peripheral nervous system.

All functional disorders in the study were classified as 'psychogenic' in origin by the treating psychiatrists. This applied even to cases where functional symptoms were grafted on to objective organic pathology; for example, when a patient with a gunshot wound to the hand developed a progressive paralysis of that hand. Such grafting of functional symptoms on to organically affected limbs or organ systems was frequently observed by physicians of WWI [48]. The one Berlin case of 'traumatic neurosis' also falls in this category because the symptoms were explained as consequences of a severe spinal injury which may explain why Bonhoeffer, who otherwise opposed Oppenheim's theory, authorised the use of this term for this patient.

\section{Psychogenic seizures}

An intriguing observation of our study is the high proportion of psychogenic seizures (28\% of cases) among German soldiers admitted to the Charité. To our knowledge, this phenomenon has not been reported in modern accounts of mental disorders resulting from combat trauma in WWI and WWII $[24,56]$. With a few exceptions mentioned below, British military doctors paid little attention to psychogenic seizures and concentrated on functional disorders concerning the heart (Disorganised Action of the Heart: DAH [9, 41, 7, 31]) and sensory-motor system (pareses, tremor, speech disorders [14]). Conversely, German psychiatrists and neurologists reported high rates of seizure disorders [10, 16, 43], and conducted studies designed to differentiate between functional seizures/hysteria and genuine epilepsy. Both Goldstein [10] and Bonhoeffer [1] thought that the psychological impact of war could not cause genuine epilepsy in an individual without a constitutional predisposition. An opposing view was expressed by Richter [43], who recognised a genuine recurrent seizure disorder ('Kriegsepilepsie' or 'war epilepsy') that could be triggered by psychological trauma even in soldiers without predisposing factors. Richter, who based his article on his research in a specialised seizure unit within a military hospital between October 1917 and May 1918, distinguished between epileptic and more common hysterical seizures by means of the psychopathological criteria established by Hoche [12], for example the duration of seizures, pupillary reactions and state of consciousness.

In Britain, White [52] recorded 'hystero-epileptic seizures with marked clonic spasms' in young soldiers but neither he nor Hurst [13] provided any statistical data on which to base their incidence. Dudley Carmalt Jones [17], who was in charge of a specialist treatment centre for shell shock, opened in January 1917 at No. 4 Stationary Hospital, conducted a detailed clinical study of functional disorders of the war. He assessed 1300 patients admitted under the label 'N.Y.D., N.' (Not yet diagnosed, nervous) a few days after the onset of symptoms but only came across 3 cases of 'violent hysterical fits'. Yealland [55], based at the National Hospital for Nervous Diseases, claimed that clonic-like fits were 'the only type of hysterical seizure that occurred in soldiers in the recent war' and that the classical arc de cercle of hysteria developed only in women and was exceedingly rare. Our records paint a different picture, with a wide range of pseudoseizures, including arc de cercle, in the soldier patients. It is currently not known whether this reflected a general difference in neurological manifestations of psychological trauma between Germany and Britain. An alternative explanation would be that certain types of manifestation were overrepresented in a secondary referral centre like the Charité. We intend to analyse records from other German and British hospitals to clarify this issue.

The changing face of post-traumatic syndromes

In the Berlin case records, we did not find evidence of posttraumatic syndromes as defined by the current diagnostic manuals. However, a small group of soldiers relived their 
traumatic combat experiences in dream-like dissociative states, mainly when waking up from a nightmare revolving around their war deployment. They showed aggressive outbursts with increased motor activity, re-staging of battle scenes (e.g. lying on the floor and shooting with an imaginary gun), unresponsiveness to external stimuli and amnesia for this episode afterwards. All received the contemporaneous diagnosis of 'psychopathic constitution' or 'hysteria'. Under the heading of 'Schreckpsychosen', similar symptoms were described by Karl Kleist, then professor of psychiatry in Rostock, in 1918 [27]. Following a shock or fright, Kleist's cases of 'anxious delirium' ('aengstliche Delirien') - the most common form of 'Schreckpsychosen'-, were in a dream-like state of consciousness, disoriented to time and place and reliving combat scenes under the influence of hallucinations. Afterwards typically hysterical symptoms became dominant again and there was amnesia for the episode. Kleist, who worked in a military hospital with a specialised psychiatric/neurological unit near the front line, also described dreams about horrifying war experiences, emotional hyperreagibility and hyperarousal as well as emotional blunting as effects of acute war trauma. These symptoms at least partly correspond to modern post-traumatic stress disorder (PTSD). Only few case records from Berlin (in addition to the 5 cases mentioned above) make a note of combat-related dreams or nightmares. More frequently, soldiers suffered from emotional blunting, detachment from other people, anhedonia and difficulties concentrating, but these symptoms lost out against the very dominant pseudoneurological and other functional symptoms. Very few soldiers had outbursts of anxiety or aggression, hypervigilance and hyperarousal. The relative rarity of this type of stress reaction and its differences from present-day PTSD support Jones's theory that similar traumatic triggers can have different phenomenological consequences in different cultural settings [18].

\section{Kleist's 'Schreckpsychosen'}

We observed that dissociative disorders (F44.1/8/9 excluding dissociative disorders of movement and sensation F44.4/5/6) only occurred in servicemen who had been exposed to combat. These cases included the acute stress reaction described above which seems to overlap with Kleist's 'Schreckpsychosen'. According to Kleist, 'Schreckpsychosen' were the most common mental disorders on the theatre of war. Unlike war neuroses which commonly developed far away from the front line and persisted for a long time, they constituted acute and short-lived reactions to combat stress and were therefore rarely seen in military hospitals at home. Although most of our soldiers had long left the combat zone (most of them had been treated in several military hospitals before being referred to the Charité), some of them showed clinical pictures resembling Kleist's Schreckpsychosen. All soldiers retrospectively diagnosed with dissociative symptoms (F44.1/8/9 excluding dissociative disorders of movement and sensation F44.4/5/ 6) and one case of 'acute stress reaction' (F43.0) strikingly resembled Kleist's 'Schreckpsychosen'. In our sample, however, we could not identify any cases with catatonic symptoms, which were also described by Kleist.

The term 'Schreckpsychose' is never mentioned in the Berlin case records. Bonhoeffer did not approve of this concept [27]. Whereas Kleist believed that the shock alone was sufficient to cause symptoms as described above, Bonhoeffer saw the wish to be ill (and to escape combat) as the main factor contributing to the development and consolidation of symptoms.

\section{Trigger events}

In most of our cases, specific events were identified that had triggered the soldier's mental breakdown (see Table 2). The documented triggers were both physical (for example, injuries obtained during front-line service or burial) and/or psychological (for example, conflict with superior). The influence of perceived intimidation or bullying by a superior was noted at the time [17]. However, almost a quarter of the patients in our sample had not seen action and presumably never been exposed to any serious hazard. This phenomenon is of relevance to the ongoing debate whether genuine stress reactions require the experience of actual physical threat or whether its mere anticipation is sufficient. Whereas the PTSD definition requires exposure to a life-threatening event (criterion A, [54]), an anticipated or feared traumatic experience was sufficient to trigger a functional disorder. This phenomenon had also been observed in British servicemen awarded a war pension for a psychological disorder [20].

In most cases, symptoms started immediately after the trigger event. There were, however, a few cases of apparent latency between the perceived trigger and onset of symptoms of up to 5 months, which supports observations made by Schneider [46] and White [52]. This phenomenon was to be replicated in the $1960 \mathrm{~s}$ with 'delayed stress syndrome' or 'post-Vietnam syndrome' and ultimately led to the formal recognition of PTSD in the DSM-III [11]. Kurt Schneider explained the delayed symptom onset in terms of medical priorities. Close to the battlefield, physicians had to concentrate on life-threatening physical injuries while the treatment of neurotic symptoms had a lower priority so that they could develop almost undetected in the aftermath of combat. Schneider also claimed that hysterical symptoms were often masked by the application of certain medications such as hyoscine (scopolamine, an 
anticholinergic drug). Furthermore, he emphasised that compensation neurosis typically developed later, away from the battlefield, making it difficult for the individual to give up his symptoms. Schneider argued that neurotic soldiers should not be sent home away from their combat units because this would reduce their chances of returning to active duty. He suggested treating them with psychotherapy immediately after their traumatic experience. Schneider observed that soldiers who were not sent to distant treatment units often showed a spontaneous recovery from functional disorders. Ernst Jolowicz [15] who saw cases of functional disorders in treatment units close to the front line confirmed Schneider's observation that neurotic symptoms consolidated in servicemen who had been evacuated from their combat unit. Because neurotic disorders appeared to have been relatively infrequent during the first few months of the war, a period of mobile warfare, he claimed that neurotic symptoms were characteristic of static trench warfare, a hypothesis that has been rephrased by modern psychiatrists [8] and historians [28, 56]. However, both our data and observations on the contagious nature of conversion disorders made at the time [44] show that exposure to trench warfare was not a requirement for the development of pseudoneurological syndromes. Jolowicz [15] also pleaded for early intervention near the battlefield to avoid pension claims, loss of manpower in combat units and unnecessary deterioration of health in the individual. At about the same time, Germany adopted the 'forward psychiatry' established by the British and French slightly earlier [23], by setting up dedicated treatment units close to the war zone [30].

\section{Treatment strategies and differences in outcome}

The prognosis of psychogenic seizure disorders was much worse than that of conversion disorders with sensory-motor symptoms. Commentators of the time noted that hysterical seizures and hysterical tremor were difficult to treat or treatment resistant [17, 34] whereas other functional disorders, such as hysterical deafness [3, 17], speech disorders and pareses [17], had a better prognosis even after long illness duration [5, 48].

The documented treatments at the Charite included eight cases of electrical stimulation of the affected body parts (with faradic brush), in two cases combined with suggestive methods, but none of the specific treatments proposed by Nonne [38] or Kaufmann [42]. A speciality of the Charité psychiatrists seems to have been therapeutic admission to the locked 'ward for the severely ill non-quiet cases', which was reported to lead to immediate cure of functional symptoms in some cases. This type of behavioural intervention seems to have been rare elsewhere in the German system.
Fitness for duty

The low rate of return to full military duty reflected a general belief among German military psychiatrists that individuals with psychopathic constitution were not suitable for front-line service [2, 6, 48, 44]. This was in contrast to the later practice in WWII, where the remit of psychiatric practice was to make traumatised soldiers fit for return to active duty [28].

Although the British came to similar conclusions [17, 52], their practice of returning soldiers with functional disorders to active duty seems to have been different. Jones [17] who carried out a study on 1,300 admissions to a specialist shell shock unit in a stationary hospital doubted that 'anyone who has once developed it (shell shock) will ever be fit for front-line soldiering within the time limit of any war'. Despite this view, about $40 \%$ of his patients without complicating organic pathology were reportedly returned to active service, about $40 \%$ to light duty or prolonged rest previous to duty and about $20 \%$ to base hospitals. He justified this course of action with the high demand for men in the combatant units: 'it has been the duty of medical officers to risk error rather in the direction of sending up possibly unfit men than in that of losing possibly fit men to their units'. With a larger standing army, the German command might have been more tolerant of medical discharge than the British. However, retrospective study of Carmalt Jones's data has shown that his published return to duty rate was exaggerated and the actual proportion of admissions that immediately returned to active duty was only $17 \%$ [21]. Yet, because of the pervasive belief in the importance of the 'psychopathic constitution', unfitness for duty did by no means lead to a successful compensation claim.

\section{Limitations}

The Charité was a specialised referral centre. It is likely that the composition of its patients differed from those in the acute war hospitals. It is difficult to obtain evidence from primary sources about differences in the patient samples between the university psychiatric departments and war hospitals close to the front line because of the scarce documentation of cases from the latter. However, based on the information from the writings of contemporaneous psychiatrists on their experience in the combat zone hospitals it is likely that they dealt with the less chronic cases, whereas the Berlin cases often came to admission after a protracted course of several months up to over a year. A quantitative diagnostic study similar to ours on records from war hospitals close to the front would certainly be desirable. 


\section{Conclusion}

A lack of knowledge regarding the aetiology and pathogenesis of functional disorders during WWI inspired an active debate and led to causal explanatory models that were shaped by culture-dependent beliefs, for example regarding a psychopathic constitution. In Germany, medical opinion shifted from a bio-medical to a more psychological explanatory framework early in the war. Some German psychiatrists even suggested that psychological trauma could cause changes in the brain leading to overt physical symptoms (Richter, 1919). It remains an open question whether the Berlin files were representative of the contemporaneous German attitude towards war-related functional disorders. To answer this question, comparable patient files from other military hospitals and treatment units would have to be analysed. However, the high proportion of hysterical seizures seen in our sample seems to be an all-German phenomenon according to the publications of the time. Intriguingly, psychogenic seizures seem to have been much rarer in Britain and did not feature prominently in any previous or subsequent war [18]. It has been recognised that war or other environmental stressors can lead to a wide range of neurological, somatic [24] or psychiatric syndromes $[33,49]$. Clinical phenomenology is likely to have been a product of the type of trauma, the medical models available at the time and other cultural factors, but their exact interplay is still a matter for research [24].

Awareness of the time-changing nature of psychological manifestations of trauma may help today's clinicians adjust their explanatory models and inform treatment approaches. The debate on the contribution of predisposing factors is also important for the medical approach to stress disorders and the attitude of society as a whole, including the evaluation of compensation claims. The flexibility of symptoms that can be triggered by largely similar patterns of psychological trauma should also be incorporated in psychobiological models of stress-induced disorders [51]. Today's clinicians should be aware that the manifestation of stressrelated disorders is influenced by the cultural and historical context. History has impressively shown that the face of post-traumatic reactions changes over time. Clinicians therefore have to be open to the possibility of new traumatically triggered syndromes appearing over time.

Acknowledgments We are grateful to the library staff at the Institute for the History of Medicine of the Charite and to Professor David Linden for diagnostic ratings. S.L. is funded by a Wellcome Trust PhD Studentship, Centre for the Humanities and Health, King's College London and British Academy Small Grant SG090329.

Conflict of interest The authors declare that they have no conflict of interest.
Open Access This article is distributed under the terms of the Creative Commons Attribution Noncommercial License which permits any noncommercial use, distribution, and reproduction in any medium, provided the original author(s) and source are credited.

\section{Appendix: Case vignette}

The cover page (see Fig. 2) included basic demographic information, such as military rank, civil occupation, marital status and religion as well as final diagnosis.

The first main section contained the history as related by the patient. Although most records did not use subheadings, this section commonly included the history of presenting illness, personal and family history, physical and emotional development, history of military service, and medical and psychiatric history. The following extracts are examples from the case of a 39-year-old joiner who was admitted in February 1918.

\section{History of presenting illness}

"Had a seizure on October 4th, 1916 after feeling very anxious and sick for a few days as he could not bear the shooting and air raids. Comrades told him that he had been crying anxiously in his sleep; had nightmares, very agitated during the day. One day he was suddenly feeling dizzy, fell to the ground, hitting his head, and was unconscious for $2 \mathrm{~h}$. Regained his consciousness in a military hospital in Sedan, then sent to military treatment unit in Mannheim for 4 weeks. Worked in Garrison until February 8th, 1917, again had a seizure, ..., everything turned black in front of his eyes, he fell to the ground and lost consciousness for $10 \mathrm{~min}$, at the same time moving arms and legs and screaming repeatedly, as he was later told by his comrades. He did not injure himself." The patient spent about a year in different war hospitals, experiencing frequent seizures and also palpitations. Before his referral to the psychiatric department of the Charité, he was treated at a military hospital in Berlin ('Barackenlazarett Tempelhof') where a seizure was observed during the physical examination: "after auscultation of the lungs increased breathing rate, slowly walking to the sofa, lying down, then moving quickly with the whole body, shouting several times, then loses consciousness, when the physician says: "now he has a seizure" he answers: "no, this is not yet the real one", trembling with the whole body, then screams again, bending his head backwards, forming an arch with his spine, see-sawing with his body, moving up and breathing heavily. After $5 \mathrm{~min}$, he is treated with the faradic brush, then lashing about, says after a while: "now everything is o.k., I can now feel everything again." " 
Personal history

"Attended school in Landskron and Neustadt in Bohemia until the age of 14; learned well. Trained as joiner for 4 years (in father's workshop), then took to the road, .... His last job (which he held for 9 years) was with the piano manufacturer 'Steinway and sons' in Hamburg."..."Married for the first time in 1904; wife died during the birth of their twin boys in 1913. Married for the second time in February 1915; living with twin sons and 2 daughters, one from 1 st, one from 2 nd wife."

\section{History of military service}

"He was conscripted to the 5th Guard Grenadier Regiment in Spandau on June 29th, 1915. On August 15th, he was transferred to the Guards supply unit because he was suffering from swollen feet.[...] After 10 days he was transferred to the railway regiment because he had had difficulties breathing and pain in his body while riding a horse." Sent to the front-line, stayed there until February 22nd, 1916, had swollen feet. After that admissions to several Military Hospitals at front-line and at home, usually following a 'seizure'.

Physical and emotional development

"Already as child soft hearted, cried easily, very irritable and excitable, angry easily, sweating easily, cold fingers; always felt sick and ran away when witnessing other people hurting each other, very sensible person, easily hurt by others, resentful."

The next section described the detailed physical and neurological examination. This was followed by a cognitive assessment, with tests of general knowledge (capital cities of Europe, enemies and allies, etc.), long- and shortterm memory (memorising figures, repeating figures), mental arithmetic, reasoning (detection of differences: child/dwarf, stream/pond, etc.), ability to abstract ("please define honour and fidelity'), attention and concentration, amending missing words to a cloze-Ebbinghaus test; description and interpretation of Binet figure.

Sample extract:

...defining abstract terms, he tries to find practical examples, for example: 'What is fidelity?'-'When a woman whose husband is at the front-line, does not cheat on him with another man.' 'What is honour?''When someone receives the Iron Cross'

\section{Course}

"In the days following his admission to the Charite, B. had several hysterical seizures, all the sudden crying out, bending back his head, forming an arch with his upper body, holding on to his mattress with his hands, see-sawing with his whole body. He was treated with the faradic brush on a daily basis,..., since February 11th, 1918 no further seizures...Still complains about trembling in his whole body, pain in the region of his heart, buzzing in his ears and constant dizziness. Wants to be discharged; with excited voice and many gestures states that life was meaningless, one should send him into battle."

Final opinion ('Schlussurteil')

"The clinical observation has shown that B. does not suffer from genuine epilepsy but seizures of a hysterical character. Under the influence of suggestive and electrical treatment the hysterical behaviour has disappeared within a few days. Increased irritability and sensitivity are signs of a pre-existing psychopathic constitution as confirmed by the patient." The patient received no compensation because the symptoms were "not caused or exacerbated by military service, but an abnormal reaction of a human being with a pathological mental predisposition to unpleasant situations. We recommend using B. as a joiner in the back area."

\section{References}

1. Bonhoeffer K (1915) Erfahrungen über Epilepsie und Verwandtes im Feldzuge. Monatsschrift für Psychiatrie und Neurologie 38:61-72

2. Bonhoeffer K (1919) Einige Schlussfolgerungen aus der psychiatrischen Krankenbewegung während des Krieges. Archiv für Psychiatrie und Nervenkrankheiten 60:721-728

3. Bostroem A (1918) Zur Psychologie und Klinik der psychogenen Hörstörungen. Zeitschrift für die gesamte Neurologie und Psychiatrie 40:307-341

4. Cohen J (1960) A coefficient of agreement for nominal scales. Educ Psychol Measur 20:37-46

5. Donath J (1918) Kriegsbeobachtungen über hysterische Stimm-, Sprach- und Hörstoerungen. Monatsschrift für Psychiatrie und Neurologie 40:301-317

6. Fraenkel F (1920) Über die psychopathische Konstitution bei Kriegsneurosen. In: Monatsschrift für Psychologie und Neurologie, pp 287-309

7. Fraser F, Wilson RM (1918) The sympathetic nervous system and the "irritable heart of soldiers". Br Med J 1918:27-29

8. Gershuny BS, Thayer JF (1999) Relations among psychological trauma, dissociative phenomena, and trauma-related distress: a review and integration. Clin Psychol Rev 19:631-657

9. Gibbes CC, Moon RO, Wells SR, Hamil P, Price FW, Goodall JS (1918) A collective investigation of ten thousand recruits with doubtful heart conditions. Br Med J 1918:248-251

10. Goldstein M (1918) Kriegserfahrungen aus dem Operationsgebiet über episodischen Bewusstseinsverlust. Archiv für Psychiatrie und Nervenkrankheiten 59:713-732

11. Healy D (1993) Images of trauma: from hysteria to post-traumatic stress disorder. Faber, London

12. Hoche AE (1902) Differentialdiagnose zwischen Epilepsie und Hysterie. Neurologisches Centralblatt 21:626 
13. Hurst AF (1918) Medical diseases of the war. Edward Arnold, London

14. Johnson W (1918) Hysterical tremor. Br Med J 1918:627-628

15. Jolowicz E (1917) Kriegsneurosen im Felde. Zeitschrift für die gesamte Neurologie und Psychiatrie 36:46-53

16. Jolowicz E (1919) Statistik über 5455 organische und funktionelle Nervenerkrankungen im Kriege. Gesichtet nach Truppenteilen, Dienstgraden, Alter, Dienstzeit, Nationalität und Berufen. Zeitschrift für die gesamte Neurologie und Psychiatrie 52: $145-162$

17. Jones DWC (1919) War-neurasthenia, acute and chronic. Brain 42:171-213

18. Jones E, Hodgins-Vermaas R, McCartney H, Everitt B, Beech C, Poynter D, Palmer I, Hyams K, Wessely S (2002) Post-combat syndromes from the Boer and Gulf war: a cluster analysis of their nature and attribution. Br Med J 324:321-324

19. Jones E, Ironside S (2010) Battle exhaustion: the dilemma of psychiatric casualties in Normandy, June-August 1944. Hist J 53:109-128

20. Jones E, Palmer I, Wessely S (2002) War pensions (1900-1945): changing models of psychological understanding. Br J Psychiatry 180:374-379

21. Jones E, Thomas A, Ironside S (2007) Shell shock: an outcome study of a First World War 'PIE' unit. Psychol Med 37:215-223

22. Jones E, Wessely S (2010) British prisoners-of-war: from resilience to psychological vulnerability: reality or perception. Twentieth Century Br Hist 21:163-183

23. Jones E, Wessely S (2003) "Forward psychiatry" in the military: its origins and effectiveness. J Trauma Stress 16:411-419

24. Jones E, Wessely S (2004) Hearts, guts and minds-somatisation in the military from 1900. J Psychosom Res 56:425-429

25. Jones E, Wessely S (2005) War syndromes: the impact of culture on medically unexplained symptoms. Med Hist 49:55-78

26. Kandel ER (1998) A new intellectual framework for psychiatry. Am J Psychiatry 155:457-469

27. Kleist K (1918) Schreckpsychosen. Allgemeine Zeitschrift für Psychiatrie und psychisch-gerichtliche Medizin 74:432-510

28. Kloocke R, Schmiedebach HP, Priebe S (2005) Psychological injury in the two world wars: changing concepts and terms in German psychiatry. Hist Psychiatry 16:43-60

29. Lemke S (2007) A historical medical study of post-traumatic stress disorders in world war I soldiers. Nervenarzt 78:92-99

30. Lerner PF (2003) Hysterical men: war, psychiatry, and the politics of trauma in Germany, 1890-1930. Cornell University Press, Ithaca

31. Lewis T (1918) Medical reports on soldiers discharged from the army for the conditions known as "DAH and "VDH". Br Med J 1918:647-650

32. Liebermeister G, Siegerist (1917) Über eine Neurosenepidemie in einem Kriegsgefangenenlager. Zeitschrift für die gesamte Neurologie und Psychiatrie 37:350-355

33. Linden SC, Harris M, Whitaker C, Healy D (2010) Religion and psychosis: the effects of the Welsh religious revival in 1904-1905. Psychol Med 40:1317-1323

34. Meyer S (1916) Die nervösen Krankheitsbilder nach Explosionsschock. Zeitschrift für die gesamte Neurologie und Psychiatrie 33:353-370

35. Micale MS, Lerner PF (2001) Traumatic pasts: history, psychiatry, and trauma in the modern age, 1870-1930. Cambridge University Press, Cambridge
36. Moerchen F (1916/1917) Der vorläufige Abschluss der Auseinandersetzung über das Wesen der nervösen Kriegsschädigungen. Psychiatrisch-Neurologische Wochenschrift 39/40:301-305

37. Neugebauer W (2000) Handbuch der preussischen Geschichte. de Gruyter, Berlin

38. Nonne M (1917) Über erfolgreiche Suggestivbehandlung der hysteriformen Störungen bei Kriegsneurosen. Zeitschrift für die gesamte Neurologie und Psychiatrie 37:191-218

39. Oppenheim H (1889) Die traumatischen Neurosen. Hirschwald, Berlin

40. Oppenheim H (1917) Stand der Lehre von den Kriegs- und Unfallneurosen. Berliner Klinische Wochenschrift 49:1169-1172

41. Oppenheimer BS, Rothschild MA (1918) The psychoneurotic factor in the "Irritable heart" Of soldiers. Br Med J 1918:29-31

42. Raether M (1917) Neurosen-Heilungen nach der KaufmannMethode. Archiv für Psychiatrie und Nervenkrankheiten 57: 489-518

43. Richter H (1919) Gibt es eine Kriegsepilepsie? Zeitschrift für die gesamte Neurologie und Psychiatrie 46:131-154

44. Rohde M (1915) Neurologische Betrachtungen eines Truppenarztes im Felde. Zeitschrift für die gesamte Neurologie und Psychiatrie 29:379-415

45. Schmidt W (1915) Die psychischen und nervösen Folgezustände nach Granatexplosionen und Minenverschüttungen. Zeitschrift für die gesamte Neurologie und Psychiatrie 29:514-542

46. Schneider K (1918) Einige psychiatrische Erfahrungen als Truppenarzt. Zeitschrift für die gesamte Neurologie und Psychiatrie 39:307-314

47. Shephard B (2001) A war of nerves: soldiers and psychiatrists in the twentieth century. Harvard University Press, Cambridge

48. Stern H (1918) Die hysterischen Bewegungsstörungen als Massenerscheinung im Krieg, ihre Entstehung und Prognose. Zeitschrift für die gesamte Psychiatrie und Neurologie 39:246-281

49. Thomas JL, Wilk JE, Riviere LA, McGurk D, Castro CA, Hoge CW (2010) Prevalence of mental health problems and functional impairment among active component and national guard soldiers 3 and 12 months following combat in Iraq. Arch Gen Psychiatry 67:614-623

50. von Sarbo A (1932) Micro-structural traumatic changes in the nervous system in the light of war experience. Schweizer Archiv für Neurologie und Psychiatrie 29:127-152

51. Vuilleumier P (2005) Hysterical conversion and brain function. In: Laureys S (ed) Boundaries of consciousness: neurobiology and neuropathology. Elsevier, Amsterdam, pp 309-329

52. White EW (1918) Observations on shell shock and neurasthenia in the hospitals in the Western command. Br Med J 1:421-422

53. Wilk JE, Bliese PD, Kim PY, Thomas JL, McGurk D, Hoge CW (2010) Relationship of combat experiences to alcohol misuse among us soldiers returning from the Iraq war. Drug Alcohol Depend 108:115-121

54. World Health Organisation (1992) International statistical classification of diseases and related health problems. World Health Organisation, Geneva

55. Yealland LR (1923) Hysterical fits, with some reference to their treatment. Lancet 2:551-555

56. Zimmermann P, Hahne HH, Biesold KH, Lanczik M (2005) Psychogenic disorders in German soldiers during World War I and II. A comparison from a psychotraumatologic perspective. Fortschritte der Neurologie und Psychiatrie 73:91-101 